\title{
Potential bias factors that affect the course evaluation of students in preclinical courses
}

\author{
Su Jin Chae ${ }^{1,2}$, Miran Kim ${ }^{2,3}$, Ki Hong Chang' ${ }^{2}$ Yoon-Sok Chung ${ }^{2,4}$ \\ ${ }^{1}$ Department of Medical Humanities \& Social Medicine, ${ }^{2}$ Office of Medical Education, Departments of ${ }^{3}$ Obstetrics \\ \& Gynecology and ${ }^{4}$ Endocrinology and Metabolism, Ajou University School of Medicine, Suwon, Korea
}

Purpose: We aim to identify what potential bias factors affected students' overall course evaluation, and to observe what factors should be considered in the curriculum evaluation system of medical schools.

Methods: This study analyzed students' ratings of preclinical instructions at the Ajou University School of Medicine. The ratings of instructions involved 41 first-year and 45 second-year medical students.

Results: There was a statistically significant difference between years of study and ratings' scoring. Learning difficulty, learning amount, student assessment, and teacher preparation from second-year students were significantly higher than first-year students $(p<0.05)$. The analysis results revealed that student assessment was the predictor of ratings from first-year students, while teacher preparation was the predictor of ratings from second-year students.

Conclusion: We found significant interactions between year of study and the students' rating results. We were able to confirm that satisfaction of instructions factors perceived by medical students were different for the characteristics of courses. Our results may be an important resource for evaluating preclinical curriculums.

Key Words: Course evaluation, Curriculum evaluation, Medical students, Preclinical curriculum, Student rating

\section{Introduction}

Since 2000, all medical schools in South Korea have conducted course evaluation of students to improve the quality of teaching [1]. Most medical schools ask students to rate the quality of their learning experience and use this feedback to improve future ratings [2,3,4]. Similarly, the majority of medical schools conduct improvement of their teaching, including curriculum evaluation of the students' rating results as a formative purpose. Furthermore, a number of medical schools utilize administrative for incentive or promotion purposes [2].

It has been indicated that the crucial factors in attaining these purposes are the validity in the ratings of students [5,6]. The widespread use of these students' rating about faculties' instruction of university has base on the belief and evidences that students' rating of instructor are valid and evaluations measure, without bias, variables that indicate effective teaching [7]. But many faculty members believe that a number of factors un-
Received: October 26, 2016 • Revised: February 24, 2017 • Accepted: April 6, 2017 Corresponding Author: Miran Kim (http://orcid.org/0000-0001-5553-5334)

Department of Obstetrics \& Gynecology, Ajou University School of Medicine, 164 World cup-ro, Yeongtong-gu, Suwon 16499, Korea

Tel: +82.31.219.5250 Fax: +82.31.219.5245 email: kmr5300@ajou.ac.kr

A part of this paper was presented at the 13th Asia Pacific Medical Education on 15 \& 16 January 2016.
Korean J Med Educ 2017 Jun; 29(2): 73-80.

https://doi.org/10.3946/kjme.2017.54

eISSN: 2005-7288

(C) The Korean Society of Medical Education. All rights reserved. This is an open-access article distributed under the terms of the Creative Commons Attribution Non-Commercial License (http:// creativecommons.org/licenses/by-nc/3.0/), which permits unrestricted non-commercial use, distribution, and reproduction in any medium, provided the original work is properly cited. 
related to teaching effectiveness bias student responses on students' instruction and course evaluation [8]. By definition, the bias in the students' rating of teaching is that it is a circumstance that unduly influences a teacher's ratings, although it has nothing to do with the teacher's teaching effectiveness [9].

A lot of researcher has been examined a number of factors that have the potential to bias students' ratings of their teacher and course, including (1) course characteristics such as class size, discipline, and difficulty level of the course; (2) student characteristics such as sex, grade point average, and attitude toward the instructor; (3) instructor characteristics such as personality, research productivity, and seductiveness; (4) circumstances under which evaluations are made such anonymity of student raters, purpose of ratings, and presence of instructor during rating $[10,11,12]$. This means that these factors are not only more importance factors, but also these factors are possible affect to students' rating of teaching.

Can the results of previous studies be applied to medical schools? The present research started with this question. The results of these prior reports have mostly been derived from studies unrelated to medical education. Since medical education differs considerably from other nonmedical settings, an analysis of factors influencing overall student ratings with a focus on medical education is critical.

Such ratings of medical students to date have been indicated to be derived from academic fields that have been irrespective of medical education environments. Since there exist distinctive features of medical education compared to higher education, an analysis of factors that influence student ratings with a specific focus on medical education settings is needed. Such differences are conceivable given that undergraduate medical curricula differ from other higher education curricula in many respects. For example, many professors and lec- turers participate in weekly teams to teach block lectures in a single medical school curriculum [13]. Medical school teaching methods are also markedly diverse. For example, most subjects place priority on laboratory and clinical training, making other educational activities such as conferences and small group learning difficult to be evaluated objectively. Current medical schools provide teaching and performance examinations that are more diversified compared to other nonmedical courses, including modalities such as problem-based learning, team-based learning, case-based learning, objective structured clinical examination, and clinical performance examination. Therefore, course evaluations in medical education must incorporate its unique features, and interpretation of obtained results should be used as a foundation for their medical curriculums [14].

The present research focuses not on the difference between medical and non-medical education, but on the structures within a preclinical courses in a single medical academic setting. Courses described herein are instruction, method of education, instructor, student, and examination. In other words, Discipline may be distinguished as basic and clinical courses, educational methods may differ according to different instructors, the number of lecturers may differ according to type of courses, and exam procedures may also be diverse within medical education courses.

In this paper, we assume that there is a difference within the preclinical courses. Our aim is to identify what potential bias factors affected the overall course evaluation of students in preclinical courses. Furthermore, we attempt to observe what factors should be considered in the application of curriculum evaluation system of medical schools. 


\section{Subjects and methods}

\section{Features of preclinical courses of Ajou University School of Medicine}

The preclinical courses in Ajou University School of Medicine (AUSOM) was divided into basic medical science and organ based integrated courses. Table 1 shows the course characteristics such as period, discipline, number of teachers, instructional methods, grading methods in first- and second-year courses. Students take part in the basic medical science instructions for 21 weeks in their first year and in the organ based integrated course for 36 weeks until the beginning of the third-year clerkship. For basic medical science instructions, the mean number of faculty per curriculum participating in the team teaching was 5.8, and the small group learning consisted of $9.9 \%$ of the total lecture time, and the students were tested once a week by written exam. On the other hand, small group learning consisted of $17 \%$ of the total lecture time for the organ based integrated course. Student assessment comprised of not only written exams, but also quizzes, oral presentations essays, and oral tests. Those faculty participating in the integrated courses numbered 21 per course.

\section{Methodology}

This study analyzed students' ratings of preclinical 22 courses at AUSOM in 2014. All first- and second-year students completed students' ratings of course evaluations using online system after final test after each course. This study involved 41 first-year and 45 secondyear medical students.

The nine dimensions of the SEEQ (Student's Evaluation of Educational Quality) were developed by Marsh [7] in 1984. The Office of Medical Education in AUSOM has developed similar systems. Questionnaire items have formulated by the Office of Medical Education were that

\section{Table 1. Course Characteristics of First- and Second-Year Curriculum}

\begin{tabular}{lll}
\hline \multicolumn{1}{c}{ Variable } & \multicolumn{1}{c}{ First year $(\mathrm{n}=41)$} & \multicolumn{1}{c}{ Second year $(\mathrm{n}=45)$} \\
\hline Period $(\mathrm{wk})$ & 21 & 36 \\
Discipline & Basic medical science & Organ based integration \\
Mean no. of teachers & 5.8 & 21.2 \\
Small group learning proportion of total instruction $(\%)$ & 9.9 & 17.7 \\
Grading method & Written exam every week & Written exam every 2 wk 10\% \\
& & formative assessment \\
\hline
\end{tabular}

Table 2. Contents of Course Evaluation

\begin{tabular}{ll}
\hline \multicolumn{1}{c}{ Factor } & \multicolumn{1}{c}{ Contents } \\
\hline 1. Learning difficulty & The course was appropriate for student's level \\
2. Learning amount & The workload of the course was appropriate \\
3. Learning objectives & Learning objectives were clear \\
4. Learning material & Learning materials posted on the online curriculum system were useful \\
5. Relevance & Contents between instructions were organically relevant \\
6. Student assessment & Student assessment tested contents actually taught \\
7. Teacher preparation & Lecturers prepared their instructions with care \\
8. Satisfaction & Overall, this instruction was satisfactory \\
\hline
\end{tabular}


learning difficulty, learning amount, objectives, materials, relevance, student assessment, teacher's preparation, and overall satisfaction (Table 2). Questionnaire of course evaluations contained eight items whereby each item represents one factor. Each item was evaluated using 5-point Likert-type scale (score of 1 indicating strongly disagree to score of 5 indicating strongly agree). The Cronbach $\alpha$ value of course evaluations was 0.86. IBM SPSS ver. 22.0 (IBM Corp., Armonk, USA) was used for statistical data analysis using t-test and multiple linear regression.

\section{Results}

\section{Differences between year of study and students' ratings of course evaluation}

Differences between years of study and students' ratings of course evaluation are shown in Table 3. Based on data learning difficulty, learning amount, student assessment, and teacher preparation, the satisfaction of second-year students was significantly $(\mathrm{p}<0.05)$ different than that of first-year students.

\section{Factors affecting students' overall satis- faction of course}

Results of multiple regression analysis stratified by year of study are shown in Table 4. Learning difficulty, learning amount, objectives, materials, relevance, student assessment, and teacher preparation had 61\% (firstyear: $F=56.05, p<0.001$ ), 62\% (second-year: $F=66.35$, $\mathrm{p}<0.001$ ) explanatory power for overall satisfaction of instructions.

In detail, significant difference between year of study and the above factors were found. For first-year students, student assessment $\quad(\beta=0.42)$, learning difficulty $(\beta=0.26)$, teacher preparation $(\beta=0.24)$, and relevance $(\beta=0.09)$, respectively, significantly explained overall satisfaction of instructions. For second-year students, teacher readiness $(\beta=0.28)$, learning amount ( $\beta=0.21)$, learning difficulty $(\beta=0.20)$, relevance $(\beta$

Table 3. Difference between Year of Study and Students' Ratings of Course Evaluation

\begin{tabular}{lccccc}
\hline \multicolumn{1}{c}{ Factor } & Year & No. & Mean \pm SD & t-value & p-value \\
\hline Learning difficulty & 1 & 255 & $3.78 \pm 0.98$ & -3.04 & 0.002 \\
Learning amount & 2 & 294 & $4.02 \pm 0.86$ & & 0.010 \\
Learning objectives & 1 & 256 & $3.60 \pm 1.05$ & -3.74 & 0.182 \\
Learning material & 2 & 293 & $3.91 \pm 0.92$ & -1.33 & 0.958 \\
Relevance & 1 & 256 & $3.89 \pm 0.93$ & 0.05 & 0.936 \\
Student assessment & 1 & 294 & $4.00 \pm 0.96$ & & \\
\multirow{2}{*}{ Teacher preparation } & 2 & 255 & $4.08 \pm 0.92$ & -0.08 & 0.001 \\
Satisfaction & 1 & 294 & $4.07 \pm 0.89$ & -3.25 & 0.047 \\
& 2 & 256 & $3.89 \pm 0.87$ & & \\
\end{tabular}

SD: Standard deviation. 
Table 4. Factors Affecting Students' Overall Satisfaction Ratings in Course Evaluation

\begin{tabular}{|c|c|c|c|c|}
\hline & \multicolumn{2}{|c|}{ First year } & \multicolumn{2}{|c|}{ Second year } \\
\hline & $\beta$ Weight & $p$-value & $\beta$ Weight & $p$-value \\
\hline Learning difficulty & 0.26 & 0.000 & 0.20 & 0.000 \\
\hline Learning amount & 0.01 & 0.763 & 0.21 & 0.000 \\
\hline Learning objective & -0.05 & 0.253 & 0.04 & 0.290 \\
\hline Learning material & 0.05 & 0.288 & 0.03 & 0.514 \\
\hline Relevance & 0.09 & 0.050 & 0.15 & 0.001 \\
\hline Student assessment & 0.42 & 0.000 & 0.10 & 0.034 \\
\hline Teacher preparation & 0.24 & 0.000 & 0.28 & 0.000 \\
\hline $\mathrm{R}^{2}$ & \multicolumn{2}{|c|}{0.62} & \multicolumn{2}{|c|}{0.62} \\
\hline Adjusted $R^{2}$ & \multicolumn{2}{|c|}{0.61} & \multicolumn{2}{|c|}{0.61} \\
\hline$F$ (p-value) & \multicolumn{2}{|c|}{$56.05 \mid<0.001)$} & \multicolumn{2}{|c|}{$66.35 \mid<0.001)$} \\
\hline
\end{tabular}

$=0.15$ ), and student assessment $(\beta=0.10)$, respectively significantly explained overall satisfaction of course $(\mathrm{p}<0.05)$.

\section{Discussion}

The students' ratings of instruction in medical education had been designated as a basic standard in medical school accreditation. Hence, the awareness and interest have increased with regard to the ratings of instruction process. Many medical schools currently employ students' ratings of course evaluations through curriculum evaluation, feedback to course directors, improvement of educational contents, and data collection to facilitate faculty appointment and promotion [15].

In this present study, we investigated the potential bias factors of curriculum influencing students' overall ratings and we attempted to ascertain whether these factors may play a role as tools in curriculum evaluation. The results observed in this study showed that students' ratings of course evaluations were significantly different when years of study were different. Scores relating to learning difficulty, learning amount, student assessment, teacher readiness, and satisfaction scores from second-year students were higher compared to those from first-year students. In other words, the satisfaction of instruction scores from second-year students who took the organ based integrated instructions were higher than those from first-year students who took basic medicine instructions. In addition, our analysis of factors affecting students' ratings of course evaluations results for each student year demonstrated that student assessment was by far the strongest predictor of overall rating for first-year students, whereas teacher preparation was the one that influenced the overall ratings of second-year students. The learning difficulty and learning amount significantly influenced ratings of instruction's results of both first and second years.

In summary, we were able to confirm that satisfaction of instructions factors perceived by medical students were different for each academic year, depending on the characteristics of each instruction. It also can provide the instructor with information on the accomplishment of particular learning outcomes and on the level of satisfaction with and influence of various courses including the planning, organizing of contents, teaching methods, grading practices, and feedback and so forth. These information can be used by the instructor to enrich and improve the course.

If this is true, then how does elucidation of factors that affect students' evaluation influence education 
restructuring and reform? After the Flexner report of 1910 [16], many educational institutions were in a dilemma as to the educational curriculum for nurturing able persons, a goal of many universities [17,18]. For example, there is a debate as to whether the medical school curriculum should be an integrated or separate basic science and clinical instruction, and if so in what manner should it be integrated or combined $[19,20]$. The students who have received basic science and humanities courses begin by facing a tremendous quantity of new learning material when entering the medical curriculum which may lead to marked stress and academic failure. To overcome these obstacles, there exists a necessity to objectively assess and ascertain what the educational process factors are that are a basis for medical school education for medical students [21].

Through results of this study, we would suggest two important messages. First, it is an improvement of the student assessment system. There are not many schools that have more examinations than medical schools. Irrespective of the type of assessment, all medical school students experience anxiety, depression, and negative psychology, and this is one of the significant factors in the assessment of curriculum assessment. University organizations should place priorities not on interuniversity competition, but should place emphasis on inter-university cooperation, should avoid anxiety inducing programs and enhance student assessment systems that are fun and interesting. In particular, we feel that there is a need for close examination of difficulty and fairness of examination perception by medical students, especially in the fields of the basic sciences,

Second, it is an improvement of the team-teaching curriculum. Teachers participate in teams to teach block lectures in preclinical curriculum. To evaluate the teaching quality of an individual teacher in multi- teacher contexts is not easy. There should be a restriction in the number of teachers who partake in the team teaching so as to strengthen the quality of the curriculum. Medical schools differ from others in that teachers provide lectures that are 1-2 hours per lecture. While this system may entail the advantages of team teaching, it is difficult to achieve uniformity within one subject and continuity within the lecture contents [13].

Obviously, this study has some limitations. First, subjects were from a single education institution with about 40 students enrolled each year. Second, the evaluation process entailed only preclinical curriculum portion, which may not represent the majority of medical schools in South Korea. Nonetheless, this investigation is a step towards addressing the evaluation of medical school curriculum.

In conclusion, we found significant interactions between year of study and the students' rating results. we identified potential bias factors that affect the course evaluation of students in preclinical courses are student assessment, teacher preparation, learning difficulty, learning amount, and satisfaction of instructions factors perceived by medical students were different for the characteristics of courses. Our results provide insight into future research pertaining to medical school curriculum evaluation.

\section{ORCID:}

Su Jin Chae: http://orcid.org/0000-0003-3060-8933;

Miran Kim: http://orcid.org/0000-0001-5553-5334;

Ki Hong Chang: http://orcid.org/0000-0002-3627-5642;

Yoon-Sok Chung: http://orcid.org/0000-0003-0179-4386

Acknowledgements: None.

Funding: None.

Conflicts of interest: None. 


\section{References}

1. Chae SJ, Choung YH, Chung YS. Factors that influence student ratings of instruction. Korean J Med Educ 2015; 27: 19-25.

2. Elzubeir M, Rizk D. Evaluating the quality of teaching in medical education: are we using the evidence for both formative and summative purposes? Med Teach 2002; 24: 313-319.

3. Donnon T, Delver H, Beran T. Student and teaching characteristics related to ratings of instruction in medical sciences graduate programs. Med Teach 2010; 32: 327-332.

4. Woloschuk W, Coderre S, Wright B, McLaughlin K. What factors affect students' overall ratings of a course? Acad Med 201 1; 86: 640-643.

5. Stratton TD, Witzke DB, Freund MJ, Wilson MT, Jacob RJ. Validating dental and medical students' evaluations of faculty teaching in an integrated, multi-instructor course. J Dent Educ 2005; 69: 663-670.

6. Schonrock-Adema J, Heijne-Penninga M, Van Hell EA, Cohen-Schotanus J. Necessary steps in factor analysis: enhancing validation studies of educational instruments. The PHEEM applied to clerks as an example. Med Teach 2009; 31: e226-e232.

7. Marsh HW. Students' evaluations of university teaching: dimensionality, reliability, validity, potential baises, and utility. J Educ Psychol 1984; 76: 707-754.

8. Howard GS, Conway CG, Maxwell SE. Construct validity of measures of college teaching effectiveness. J Educ Psychol 1985; 77: 187-196.

9. Centra JA. Reflective faculty evaluation: enhancing teaching and determining faculty effectiveness. San Francisco, USA: Jossey-Bass; 1993.

10. Feldman KA. Class size and college students' evaluations of teachers and courses: a closer look. Res High Educ
1984; 21: 45-116.

11. Feldman KA. College students' views of male and female college teachers: part I. evidence from the social laboratory and experiments. Res High Educ 1992; 33: 317-375.

12. Hofman JE, Kremer L. Attitudes toward higher education and course evaluation. J Educ Psychol 1980; 72: 610-617.

13. Stratton TD, Witzke DB, Jacob RJ, Sauer MJ, Murphy-Spencer A. Medical students' ratings of faculty teaching in a multi-instructor setting: an examination of monotonic response patterns. Adv Health Sci Educ Theory Pract 2002; 7: 99-116.

14. Leamon MH, Fields L. Measuring teaching effectiveness in a pre-clinical multi-instructor course: a case study in the development and application of a brief instructor rating scale. Teach Learn Med 2005; 17: 119-129.

15. Chae SJ, Lim KY. An analysis of course evaluation programs at Korean medical schools. Korean J Med Educ 2007; 19: 133-142.

16. Beck AH. The Flexner report and the standardization of American medical education. JAMA 2004; 291: 2139-2140.

17. Frank JR, Snell LS, Cate OT, Holmboe ES, Carraccio C, Swing SR, Harris P, Glasgow NJ, Campbell C, Dath D, Harden RM, Iobst W, Long DM, Mungroo R, Richardson DL, Sherbino J, Silver I, Taber S, Talbot M, Harris KA. Competency-based medical education: theory to practice. Med Teach 2010; 32: 638-645.

18. Huang L, Cheng L, Cai Q, Kosik RO, Huang Y, Zhao X, Xu GT, Su TP, Chiu AW, Fan AP. Curriculum reform at Chinese medical schools: what have we learned? Med Teach 2014; 36: 1043-1050.

19. Bandiera G, Boucher A, Neville A, Kuper A, Hodges B. Integration and timing of basic and clinical sciences education. Med Teach 2013; 35: 381-387.

20. Brauer DG, Ferguson KJ. The integrated curriculum in 
Su Jin Chae, et al: Factors affecting course evaluation

medical education: AMEE guide no. 96. Med Teach 2015; 37: 312-322.

21. Chae SJ, Kim M, Chang KH. Longitudinal analysis of the effect of academic failure tolerance on academic achievement fluctuation in medical school students. Korean J Med Educ 2016; 28: 25-28. 